\title{
PRODUÇÃO DA CULTURA DA ALFACE (Lactuta sativa L.) EM FUNÇÃO DAS LÂMINAS DE IRRIGAÇÃO E TIPOS DE ADUBOS
}

\author{
Márcio Aurélio Lins dos Santos ${ }^{1 *}$, Daniella Pereira dos Santos ${ }^{1}$, Sirleide Maria de Menezes ${ }^{1}$, Dayane Farias \\ Lima$^{1}$, Jânio Pedro da Silva Vieira ${ }^{1}$
}

${ }^{1}$ Universidade Federal de Alagoas, Campus Arapiraca. Av. Manoel Severino Barbosa, Bom Sucesso CEP: 57309-005. Arapiraca - AL

*Autor para correspondência: mal.santo@arapiraca.ufal.br

RESUMO: A alface (Lactuta sativa L.) é uma das hortaliças mais consumida em todo o mundo, tendo seu cultivo um alto consumo de água, uma vez que a Região Nordeste apresenta déficit hídrico e distribuição de precipitações irregulares durante 0 ano, se tornando necessário o uso racional da água para irrigação. Objetivo-se avaliar a produtividade da cultura da alface em função de diversas lâminas de água e diferentes tipos de adubos. 0 experimento foi conduzido na área experimental do Grupo Irriga do Campus de Arapiraca da UFAL. $O$ delineamento experimental foi conduzido em blocos casualizados contendo parcelas e subparcelas, em arranjo fatorial $3 \times 3 \times 4$, com três blocos, três níveis de laminas de água (50; 100 e 150\% da ETc) e quatro tipos de adubação (testemunha (sem adubação); esterco bovino; esterco de aves; fertilizante químico). Foi utilizado o sistema de irrigação por gotejamento. As variáveis analisadas foram: número de folhas (NF), área média das folhas (AMF), massa fresca da parte aérea (MFPA), massa fresca da raiz (MFR), massa seca da parte aérea (MSPA) e massa seca da raiz (MSR). Neste sentido, pode-se concluir que a cultura da alface respondeu significativamente a todas as lâminas aplicadas, sendo a lâmina correspondente a $150 \%$ da ETc a que apresentou os melhores resultados para todas as variáveis analisadas. Não houve efeito significativo para os tipos de adubo e nem para lâminas associadas aos tipos de adubos para as variáveis analisadas.

PALAVRAS-CHAVE: Evapotranspiração, manejo de água, irrigação.

\section{PRODUCTION OF THE CULTURE OF THE LETTUCE (Lactuta sativa L) IN FUNCTION OF THE IRRIGATION SLIDES AND TYPES OF FERTILIZERS}

\begin{abstract}
The lettuce (Lactuta sativa L.) is one of the most commonly consumed vegetables worldwide, having its cultivation a high water consumption, since the Northeast region presents water deficit and irregular precipitations distribution during the year, if making necessary the rational use of water for irrigation. Objective was to evaluate productivity the lettuce crop in function to diverse water slides and different types of fertilizers. The experiment was conducted in the experimental area of the Irriga Group of the Arapiraca Campus of the Federal University of Alagoas. The experimental design was conducted a randomized block containing plots and sub plots, in the $3 \times 3 \times 4$ factorial arrangement, with three blocks, three levels of water slides (50, 100 and $150 \%$ of ETc) and four types of fertilization (control (without fertilization), cattle manure, chicken manure, chemical fertilizer). Was used the drip irrigation system. The variables analyzed were: number of leaves $(L N)$, average area of the leaves (AAL), fresh weight of the aerial part (FWAP), fresh weight of the root (FWR), dry weight of the aerial part (DWAP) and dry weight of root (DWR). In this sense, it can be concluded that the culture of lettuce significantly responded to all water slides applied, the corresponding blade to $150 \%$ of ETc presented the best results for all variables analyzed. There was no significant effect for the types of fertilizer nor for blades associated with the types of fertilizers to the variables.
\end{abstract}

KEY WORDS: Evapotranspiration, water management, Irrigation. 


\section{INTRODUÇÃO}

Coma decadência da cultura do fumo no município de Arapiraca (AL), as hortaliças (alface, coentro, cebolinha verde, couve-flor) vêm tendo crescente importância na Região Agreste Alagoana e no cenário estadual, tanto por suas características de alta produtividade, alta rentabilidade e capital investido, quanto pela sua importância social para o emprego do elevado número de mão-de-obra das áreas oriundas da fumicultura.

A alface (Lactuca sativa L.) é a principal hortaliça folhosa comercializada e consumida pela população brasileira, pela facilidade de aquisição e por ser produzida durante 0 ano inteiro (Oliveira et al., 2004). Esse fato é devido o curto ciclo de produção e de sua colheita aos trinta dias após o transplantio, portanto, o cultivo dessa hortaliça nas condições climáticas da Região Agreste de Alagoas e com manejo adequado da irrigação poderá ser produzida semanalmente.

É cultivada tradicionalmente por pequenos produtores, que confere grande importância econômica e social, sendo significativo fator de agregação do homem do campo (Villas Bôas et al., 2004). Os hábitos alimentares da população evidenciam essa condição que é favorecida pela fácil aquisição do produto, pelo seu sabor, pela qualidade nutritiva e por ser uma hortaliça de baixo custo (Cometti et al., 2004).

0 desenvolvimento vegetativo da alface é afetado diretamente pela umidade do solo, sendo necessária uma aplicação de água com maior frequência e menor intensidade de aplicação ao longo do ciclo da cultura (Santos e Pereira, 2004), ou seja, aplicar pequenas lâminas de água com menor intervalo entre irrigações (menor turno de rega).

A disponibilidade hídrica no Nordeste é preocupante pela irregularidade das chuvas e longos períodos de secas. Sendo aágua fator limitante também no AgresteAlagoano, se tornando necessária a otimização do uso da água para irrigação da cultura da alface. 0 manejo de irrigação deve ser considerado prática importante para obtenção de alta qualidade e produtividade da cultura (Bernardo et al., 2013). Sendo importante não apenas por suprir as necessidades hídricas das plantas, mas também por minimizar problemas com doenças e lixiviação de nutrientes, bem como gastos desnecessários com água e energia (Koetz et al., 2006).

Para que possa haver um aumento na produtividade da alface cultivada em Arapiraca, cidade situada no Agreste alagoano, havendo um uso requerido da água, é necessário determinar a quantidade ideal de água, que pode ser estimada por meio da determinação da função produção da cultura relacionando suas necessidades hídricas com tipos de adubos. A função de produção mostra a quantidade física obtida do produto a partir da quantidade física utilizada e dos fatores de produção em determinado período de tempo (Vasconcellos, 2007).

Logo, a necessidade de implantação da irrigação, antes não usada, torna-se imprescindível que haja um uso racional da água disponível através do manejo adequado da irrigação na cultura da alface. Objetivo-se avaliar a produtividade da cultura da alface (Lactuta sativa L.) em função de diversas lâminas de água e diferentes tipos de adubos cultivados na região Agreste do Estado de Alagoas

\section{MATERIAL E MÉTODOS}

O trabalho foi desenvolvido na área experimental do Grupo de Pesquisa em Manejo de Água para Irrigação (Grupo IRRIGA) do Campus de Arapiraca da Universidade Federal de Alagoas (UFAL), no período de março a abril de 2013, localizada no município de Arapiraca, situada a $9^{\circ} 45^{\prime} 58^{\prime \prime}$ de latitude sul e $35^{\circ} 38^{\prime} 58^{\prime \prime}$ de longitude oeste e altitude de $264 \mathrm{~m}$. Na região Agreste do Estado de Alagoas, área de transição entre a Zona da Mata e o Sertão Alagoano, cujo solo é classificado como Latossolo Amarelo Vermelho Distrófico (Embrapa 2006). Seu clima é classificado como do tipo 'As' tropical, com estação seca de verão pelo critério de classificação de Köeppen. Os dados físico-hídrico e químico da área estão dispostos nas Tabelas 1 e 2.

$O$ delineamento experimental foi conduzido em blocos casualizados contendo parcelas e subparcelas, sob o arranjo fatorial $3 \times 3 \times 4$. Aárea experimental total é de $60,0 \mathrm{~m}^{2}(4,0 \times 20,0 \mathrm{~m})$ foi dividida em três blocos 20,0 $\mathrm{m}^{2}$ (4,0 $\times 5,0 \mathrm{~m})$, cada bloco contém três parcelas de 4,0 $\mathrm{m}^{2}$ $(4,0 \times 1,0 \mathrm{~m})$ e cada parcela, quatro subparcelas de 1,0 $m^{2}(1,0 \times 1,0 \mathrm{~m})$ cada, com espaçamento de $0,25 \mathrm{~m}$ entre plantas e entre linhas. 0 arranjo fatorial foi distribuído da seguinte forma: três repetições correlacionando três níveis de lâminas de água (50; 100 e $150 \%$ da ETc) e quatro tipos de adubação (testemunha (sem adubação); esterco bovino; esterco de aves; adubo químico). Foram transplantas 16 mudas por subparcelas, 64 por parcelas e 192 plantas por bloco, totalizando 576 plantas. Para realização das analises foram usadas às quatro plantas centrais em cada subparcela. 
Tabela 1. Analise físico-hídrica do solo da área experimental do Campus de Arapiraca (UFAL), 2013.

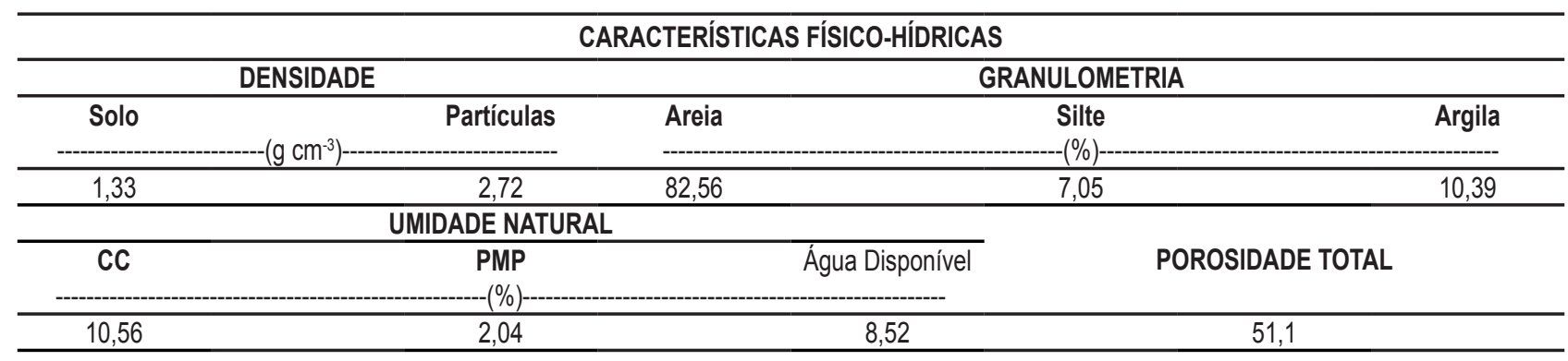

Tabela 2. Análise química do solo da área experimental do Campus de Arapiraca (UFAL), 2013.

\begin{tabular}{|c|c|c|c|c|c|c|c|c|}
\hline \multicolumn{9}{|c|}{ CARACTERÍSTICAS QUÍMICAS } \\
\hline \multirow{3}{*}{$\begin{array}{l}\text { PROFUNDIDADE } \\
(\mathrm{cm})\end{array}$} & \multirow{2}{*}{\multicolumn{2}{|c|}{$\begin{array}{c}\mathbf{P} \\
\left(\mathrm{mg} \mathrm{dm}^{-3}\right)\end{array}$}} & $\mathrm{K}$ & $\mathrm{Ca}$ & Mg & $\mathrm{H}+\mathrm{Al}$ & CTC & Al \\
\hline & & & & & $--(\mathrm{cmo}$ & & & - \\
\hline & \multicolumn{2}{|c|}{11} & 109 & 1,4 & 0,8 & 1,2 & 3,73 & 0,2 \\
\hline \multirow{3}{*}{$0,0-20,0$} & $\mathrm{pH}$ & M.O & V & CTC & $\mathrm{Fe}$ & $\mathrm{Cu}$ & $\mathrm{Zn}$ & $\mathrm{Mn}$ \\
\hline & $\left(\mathrm{H}_{2} \mathrm{O}\right)$ & $(\%)$ & $(\%)$ & $\left(\mathrm{cmol} \mathrm{dm}^{-3}\right)$ & - & 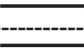 & -1--- & --- \\
\hline & 5,6 & 1,07 & 67,8 & 3,73 & 66,16 & 0,71 & 2,78 & 39,68 \\
\hline
\end{tabular}

Para aplicação da lâmina de água na cultura da alface cv. Americana, (Lactuca sativa L.) foi utilizada o sistema de irrigação por gotejamento. Os níveis de lâminas de água utilizados foram: $W_{1}(50 \%$ da ETc), $W_{2}\left(100 \%\right.$ da ETc) e $W_{3}(150 \%$ da ETc), determinada pela evapotranspiração da cultura (ETc) e estimada pelo produto da evapotranspiração de referência (ETo) pelo coeficiente de cultivo $(\mathrm{Kc})$ da cultura. Para estimar a ETo foi utilizado o método de Hargreaves-Samani com os dados coletados no Instituto Nacional de Meteorologia (INMET) da estação localizada à $8,0 \mathrm{~km}$ da área experimental do Grupo IRRIGA, no Povoado Baatinga no município de Arapiraca (AL).

Para estimativa da (ETo) diária, em mm dia-1, foi utilizado a Equação 1, definida pelo método de HargreavesSamani, apresentada por (Pereira et al., 1997).
$E T o=0,023 \cdot R \cdot(T+\mathbb{T}, 8) \cdot \sqrt{T_{\max }-T_{\min }}$

Em que:

$E T o=$ evapotranspiração de referência, $\mathrm{mm} \mathrm{dia}^{-1}$;

$\mathrm{Ra}=$ saldo de radiação, $\mathrm{mm} \mathrm{dia}^{-1}$;

$\mathrm{T}=$ temperatura média diária, ${ }^{\circ} \mathrm{C}$;

$\mathrm{T}_{\max }=$ temperatura máxima, ${ }^{\circ} \mathrm{C}$;

$\mathrm{T}_{\min }=$ temperatura mínima, ${ }^{\circ} \mathrm{C}$.

Para calcular a evapotranspiração da cultura da alface foi utilizada a Equação 2. Os coeficientes de cultivo utilizados neste trabalho estão apresentados na Tabela 3, os valores de $\mathrm{K}_{\mathrm{c}}$ recomendados para a alface cultivada em condições de campo são respectivamente 0,85; 1,05; e 0,95 para os estádios da cultura inicial, intermediário e final (adaptado de Allen et al., 1998; Marouelli et al. (2011)).

Tabela 3. Coeficientes de cultivo (Kc) para a cultura da alface, estádio da cultura (FASE), dias após o transplantio (DAT) e o coeficiente de cultivo (Kc).

\begin{tabular}{c|c|c}
\hline FASE & DAT & Kc \\
\hline Inicial & $0-10$ & 0,85 \\
Intermediário & $11-20$ & 1,05 \\
Final & $21-30$ & 0,95 \\
\hline
\end{tabular}

Adaptado de Allen et al. (1998) e Marouelli et al. (2011).

$\mathrm{ETc}=\mathrm{ETo} \cdot \mathrm{Kc}$

Em que:

ETc: Evapotranspiração da cultura da alface ( $\left.\mathrm{mm} \mathrm{dia}^{-1}\right)$;

ETo: Evapotranspiração de referência pelo método de Hargreaves-Samani (mm dia-1);
(2) Kc: O coeficiente de cultivo da alface (adimensional).

Inicialmente foi realizado um preparo do solo convencional com uma aração seguida de uma gradagem, depois foi feita as incorporações dos adubos conforme 
sorteio de cada subparcela, sendo o adubo orgânico (estercos: bovino e de aves) aplicado 15 dias antes do plantio e a aplicação do adubo químico na fundação.

A aplicação da adubação orgânica foi baseada em Filgueira (2007), onde foi estabelecida para esterco de bovino $5,0 \mathrm{~kg} \mathrm{~m}^{-2}$, totalizando $45,0 \mathrm{~kg}$ para os três blocos e para 0 esterco de ave foi recomendado a quantidade de um terço da recomendação de esterco bovino, $1,80 \mathrm{~kg} \mathrm{~m}^{-2}$, totalizando $16,0 \mathrm{~kg}$ para todo 0 experimento. Já para adubação química foi realizado análise do solo (Tabela 2), no qual estabeleceu a recomendação de adubo mineral na fórmula NPK (414-8), com $200 \mathrm{~g} \mathrm{~m}^{-2}$, totalizando $1,80 \mathrm{~kg}$. Para efeito de interação as lâminas de água foram correlacionadas com os tipos de adubo (testemunha, esterco bovino, esterco de ave e adubo mineral).

As mudas foram adquiridas com produtores da região, e se encontravam com 20 dias após a semeadura, sendo transplantada no dia 11 de março de 2013. Durante aos quatorze primeiros dias após o transplantio (DAT), as plantas foram irrigadas com regadores, para logo em seguida no dia 25 de Março de 2013, nos 15 DAT ser implantado o sistema de irrigação. 0 sistema de irrigação utilizado foi 0 localizado por gotejamento sob gravidade, onde os gotejadores estavam espaçados a 0,20 m. Cada parcela experimental possuía duas fitas de mangueiras gotejadoras, sendo que cada fita atendeu a duas linhas de plantas. 0 monitoramento foi feito diariamente, realizando-se o controle manual de ervas daninhas e a limpeza do sistema de irrigação.

A colheita da cultura da alface foi realizada aos 40 DAT, onde foram realizadas avaliações das varáveis analisadas foram: número de folhas (NF), área média das folhas (AMF), massa fresca da parte aérea (MFPA), massa fresca da raiz (MFR), massa seca da parte aérea (MSPA), massa seca da raiz (MSR) e massa seca total (MST). Sendo as massas secas obtidas após a secagem em estufa com ventilação de ar forçado por 72 horas a $65^{\circ} \mathrm{C}$, para a posterior pesagem em balança analítica. Os dados foram submetidos à análise de variância com teste $F$ e Regressão, pelo software $R$, e com o software SISVAR.

\section{RESULTADOS E DISCUSSÃO}

Os resultados obtidos encontram-se na Tabela 4, onde se pode observar um aumento em todas variáveis analisadas para cada nível de lâmina: NF (número de folhas) teve crescimento de 1,5 na razão de $W_{2}$ para $W_{1}$ e de 2,2 de $W_{3}$ para $W_{2}$. Já a AMF (área média das folhas) as médias tiveram acréscimo respectivos na razão de 1,9 e 1,7 de $W_{2}$ para $W_{1}$ e de $W_{3}$ para $W_{2}$.

Tabela 4. Médias para as variáveis analisadas: número de folhas (NF), área média das folhas (AMF), massa fresca da parte aérea (MFPA), massa fresca da raiz (MFR), massa seca da parte aérea (MSPA) e massa seca da raiz (MSR).

\begin{tabular}{ccccccc}
\hline \multirow{2}{*}{ LÂMINA } & \multicolumn{7}{c}{ MÉDIA } \\
\cline { 2 - 7 } & $\begin{array}{c}\text { NF } \\
\text { (unid./planta) }\end{array}$ & $\begin{array}{c}\text { AMF } \\
\text { (cm²/planta) }\end{array}$ & $\begin{array}{c}\text { MFPA } \\
\text { (g/planta) }\end{array}$ & $\begin{array}{c}\text { MFR } \\
\text { (g/planta) }\end{array}$ & $\begin{array}{c}\text { MSPA } \\
\text { (g/planta) }\end{array}$ & $\begin{array}{c}\text { MSR } \\
\text { (g/planta) }\end{array}$ \\
\hline $50 \%$ ETc & 8,5 & 7,5 & 28,8 & 1,7 & 3,8 & 0,8 \\
$100 \%$ ETc & 12,5 & 14,5 & 101,1 & 4,4 & 9,6 & 1,2 \\
$150 \%$ ETc & 27,0 & 24,4 & 223,6 & 11,4 & 23,3 & 2,4 \\
\hline
\end{tabular}

As variáveis MFPA e MFR (massas frescas da parte aérea e da raiz). A MFPA obteve por plantas amostradas um acréscimo no produto de $3,5 \mathrm{~W}_{1}$ igual a $\mathrm{W}_{2}$; e, de $2,2 \mathrm{~W}_{2}$ igual a $\mathrm{W}_{3}$. $\mathrm{A}$ MFR obteve incremento igual para cada nível, $W_{2}$ igual 2,6 $\mathrm{W}_{1}$ e $\mathrm{W}_{3}$ igual 2,6 $\mathrm{W}_{2}$. Já nas vaiáveis MSPA e MSR (massas secas da parte aérea e da raiz) se observou acréscimo nas razões de $W_{2}$ para $W_{1}$ e de $W_{3}$ para $W_{2}$ de 2,$4 ; 2,5 ; 1,5$ e 2,0, respectivamente.
De acordo com os dados obtidos houve resultado significativo a $1 \%$ e $0,1 \%$ de probabilidade de erro pelo teste "F" para todas as lâminas aplicadas, já para os tipos de adubo não houve diferenças significativas para todas as variáveis analisadas. Verificou-se efeito significativo das lâminas de água para número de folhas (NF), área média das folhas (AMF), massa fresca da parte aérea (MFPA), massa fresca da raiz (MFR), massa seca parte aérea (MSPA) e massa seca da raiz (MSR) os quais estão apresentados nas Tabelas 5. 
Tabela 5. Análise de variância da cultura da alface c. Americana em função de lâminas de irrigação e tipos de adubos: número de folhas (NF), área média das folhas (AMF), massa fresca da parte aérea (MFPA), massa fresca da raiz (MFR), massa seca da parte aérea (MSPA) e massa seca da raiz (MSR).

\begin{tabular}{cccccccc}
\hline \multirow{2}{*}{ CAUSA DE VARIAÇÃO } & \multirow{2}{*}{ GL } & \multicolumn{9}{c}{ QM } \\
\cline { 3 - 8 } & & NF & AMF & MFPA & MFR & MSPA & MSR \\
\hline Lâmina (L) & 2 & $454,11^{*}$ & $277,22^{*}$ & $47,28^{* *}$ & $95,11^{* *}$ & $326,35^{*}$ & $1,62^{*}$ \\
Blocos & 2 & 32,72 & 81,02 & 19,03 & 2,17 & 31,01 & 0,35 \\
Erro (a) & 4 & 18,92 & 12,30 & 5,05 & 1,52 & 11,33 & 0,08 \\
Adubo (A) & 3 & $14,43^{\text {ns }}$ & $15,37^{\text {ns }}$ & $11,77^{\text {ns }}$ & $2,94^{\text {ns }}$ & $6,93^{\text {ns }}$ & $0,13^{\text {ns }}$ \\
Lx A & 6 & $10,93^{\text {ns }}$ & $2,28^{\text {ns }}$ & $5,09^{\text {ns }}$ & $1,22^{\text {ns }}$ & $7,37^{\text {ns }}$ & $0,16^{\text {ns }}$ \\
Erro (b) & 18 & 11,15 & 9,03 & 10,05 & 1,67 & 8,85 & 0,11 \\
C.V. (a) \% & & 41,80 & 34,15 & 33,00 & 33,40 & 51,60 & 46,70 \\
\hline C.V. (b) \% & & 32,00 & 29,50 & 46,50 & 35,00 & 45,60 & 54,70 \\
\hline
\end{tabular}

ns não significativo, ${ }^{*} e^{* *}$ significativo pelo teste "F" respectivamente à $1 \%$ e $0,1 \%$ de probabilidade de erro

De acordo com a Tabela 5 a cultura da alface respondeu significativamente a todos os níveis de água (W), onde para as variáveis: número de folhas (NF), área média das folhas (AMF), massa seca da parte aérea (MSPA) e massa seca da raiz (MSR) houve um nível de significância a $1 \%$ de probabilidade de erro pelo teste $F$. Massa fresca da parte aérea (MFPA) e massa fresca da raiz (MFR) essa probabilidade de erro foi de $0,1 \%$ pelo referido teste.

É possível observar que as maiores médias para todas as variáveis foram obtidas através da lâmina de $150 \%$ da ETc. Em avaliação de diferentes lâminas de água na cultura da alface no Agreste Alagoano as lâminas de irrigação equivalente a 100 e $125 \%$ da ETo proporcionaram maiores desenvolvimento em todas as variáveis analisada: altura da planta, diâmetro do caule, crescimento e número de folhas (Silva et al., 2012). A máxima produtividade comercial foi estimada com a aplicação da lâmina correspondente ao fator de reposição de 98 \% (Lima Júnior et al., 2012).

Estudos com irrigação por gotejamento observou que a lâmina de $50 \%$ da ETc, com base na estimativa do tanque classe $\mathrm{A}$, apresentou a menor produtividade quando comparado com as demais lâminas, onde também foi encontrada as menores médias em relação as variáveis analisadas, nas variáveis diâmetro da cabeça, massa fresca e massa seca, a concavidade da curva voltada para cima indicou um aumento proporcional de produção em relação à disponibilidade de água para a cultura (Noreto et al., 2012).

O efeito quadrático para circunferência da cabeça comercial da alface americana, cujo valor máximo de circunferência foi de $44,94 \mathrm{~cm}$, com uma lâmina total de água de 170,81 mm, correspondente a $91,66 \%$ da lâmina de reposição (Silva et al., 2008).

Levando em conta os resultados obtidos no experimento pode-se afirmar que a lâmina de 150\% foi a que obteve uma melhor média; já em relação aos diferentes tipos de adubo (esterco bovino, esterco de ave e mineral) não houve efeito significativo para nenhuma das características avaliadas de acordo com o programa estatístico $R$ (Tabela 5).

Observou-se através da análise de regressão linear que houve um acréscimo na produção para cada variável analisada (número de folhas, área média das folhas, massa fresca da parte aérea, massa fresca da raiz, massa seca da parte aérea e massa seca da raiz) de acordo com as diferentes lâminas de água, sendo a maior produção na $W_{3}(150 \%)$. Lima et al. (2014) apresentou resultados semelhantes com lâminas aplicadas na cultura da Alface cv. Americana respondeu significativamente as lâminas aplicadas equivalentes a $50 \%, 100 \%$ e $150 \%$ da ETc, sendo na lâmina de $150 \%$ a obtenção das maiores médias.

Uma maior eficiência de uso da água foi encontrada na produção total e comercial da alface para as lâminas com base em $25 \%$ e $50 \%$ da evaporação do tanque classe $A$ aplicadas através de irrigação por gotejamento subsuperficial (Gomes e Souza, 2002). Os níveis de irrigação (50 e 100\% da evapotranspiração) nas plantas de alface não influenciaram nas variáveis analisadas: altura, número de folhas, diâmetro de copa, massa de matéria fresca e massa de matéria seca da parte aérea (Chiconato et. al, 2013).

Para a variável número de folhas (NF) cada aumento de unidade de número de folhas teve um 
aumento constante de $0,118 \%$ na lâmina de água. A variável área média das folhas (AMF) mostrou um aumento constate de $0,095 \%$ de acordo com cada lâmina de água. Já na variável massa fresca da parte aérea (MFPA) obteve um aumento constante de 1,234\% de acordo com cada lâmina de água.

No presente trabalho, certamente, as doses de nitrogênio promoveram um desbalanço nutricional, contribuindo para a redução nos valores da MFPA. Trabalhando com adubação orgânica, encontraram para MFPA da alface cv. Verônica 318,2 g planta-1 ${ }^{-1}$ para a dose máxima $\left(86,4 \mathrm{t} \mathrm{ha}^{-1}\right)$ de composto (Silva et al., 2010). Contrariamente, observaram que a adubação orgânica exclusiva com esterco bovino, na quantidade de 13 t ha-1 $^{-1}\left(1,3 \mathrm{~kg} \mathrm{~m}^{-2}\right)$, não contribuiu de forma efetiva para 0 aumento de produtividade da alface cv Vera "tipo crespa" (Almeida et al., 2008). Possivelmente pela baixa dosagem do adubo orgânico utilizado no experimento. A MFPA respondeu de forma quadrática à adubação química nitrogenada, mesmo com a adição de adubo orgânico (Resende et al., 2009).

A variável massa fresca da raiz (MFR) obteve um aumento constante de 0,056\%, a variável massa seca da parte aérea (MSPA) esse aumento constante foi de $0,102 \%$ na produção de acordo com cada lâmina de água. Bem como para massa seca da raiz o aumento constante foi de 0,007\% para cada lâmina de água.

Neste sentido, pode-se concluir que a cultura da Alface respondeu significativamente a todas as lâminas aplicadas, sendo a lâmina correspondente a $150 \%$ da ETc a que apresentou os melhores resultados para todas as variáveis analisadas: número de folhas, área média das folhas, massa fresca da parte aérea, massa fresca da raiz, massa seca da parte aérea, massa seca da raiz e massa seca total. Não houve efeito significativo para os tipos de adubo e nem para lâminas associadas aos tipos de adubos para nenhuma das variáveis analisadas.

\section{REFERÊNCIAS BIBLIOGRÁFICAS}

ALLEN, R.G.; PEREIRA, L.S; RAES, D.; SMITH, M. Crop evapotranspiration: guidelines for computing crop water requirements. Roma, FAO, Irrigation and Drainage (Paper 56). 300p. 1998.

ALMEIDA M. M. T. B; LIXAA. T.; SILVAE. E.; AZEVEDO P. H. S.; POLLI H.; RIBEIRO R. L. D. Fertilizantes de leguminosas como fontes alternativas de nitrogênio para produção orgânica de alface. Pesquisa Agropecuária Brasileira, 2008, 43, 675-682.

BERNARDO, S., SOARES, A. A., MANTOVANI, E. C. Manual de irrigação. 8. Ed. Viçosa: Ed. UFV, p.9, 2013.

COMETTI, N. N. Composto nitrogenado e açucares solúveis em tecidos de alface orgânica, hidropônica e convencional. Horticultura Brasileira, 2004, 22, 4, 748753

CHICONATO, D. A.; SIMONI, F. DE; GALBIATTI, J. A.; FRANCO, C. F.; CARAMELO, A. D. Resposta da alface à aplicação de biofertilizante sob dois níveis de irrigação. Bioscience Journal, 2013, 29, 2, 392-399.

Embrapa. Centro Nacional de Pesquisa de Solos. Sistema Brasileiro de Classificação de Solos. 2 ed. Rio de Janeiro: Embrapa Solos, 2006.

FILGUEIRA, F. A. R. Novo manual de olericultura: Agricultura na produção e comercialização de hortaliças. 3 ed. Viçosa, MG. Editora. UVE, 402p. 2007.

GOMES, E. P.; SOUZA, A. DE P. Produtividade da alface (Lactuca sativa L.) em função dos valores de lâminas de água aplicados por gotejamento superficial e subsuperficial. Revista Irriga, 2002, 7, 1, 35-41.

KOETZ, M.; COELHO, G.; COSTA, C. C. C.; LIMA, E. P.; SOUZA, R. J. Efeito de doses de potássio e da frequência de irrigação na produção da alfaceamericana em ambiente protegido. Engenharia Agrícola, 2006, 26, 3, 730-737.

LIMA, D. F.; MENEZES, S. M.; SILVA, J. P. V.; ALVES, E. DA S.; SANTOS, D. P.; SANTOS, M. A. L. Análise de desenvolvimento da cultura da alface sob lâminas de água e diferentes tipos de adubação. $2^{\circ}$ INOVAGRI International Meeting. Fortaleza (CE), 2014.

LIMA JÚNIOR, J. A. DE L.; PEREIRA, G. M.; GEISENHOFF, L. O.; VILAS BOAS, R. C.; SILVA, W. G. DA; SILVA, A. L. P. DA. Produtividade da alface americana submetida a diferentes lâminas de irrigação. Semina: Ciências Agrárias, 2012, 33, suplemento 1, 2681-2688. 
MAROUELLI, W. A. ; OLIVEIRA, A. S. ; COELHO, E. F.; NOGUEIRA, L. C.; SOUSA, V. F. Manejo da água de irrigação. In: Sousa, V. F.; Marouelli, W. A.; Coelho, E. F.; Pinto, J. M.; Coelho Filho, M. A. (Org.). Irrigação e fertirrigação em fruteiras e hortaliças. Brasília: Embrapa Informação Tecnológica, 2011.

NORETO, L. M.; MATTIELLO, V. D.; PARO, P.; KLEIN, J.; RICIERI, R. P.; SANTOS, R. F.; FAGUNDES, R. S. Produção de alface submetida a diferentes frações de irrigação. Cultivando o Saber, 2012, 5, 2, 157-164.

OLIVEIRA, A. C. B.; SEDIYAMA, M. A. N.; PEDROSA, M. W.; GARCIA, N. C. P.; GARCIA, S. L. R. Divergência genética e descarte de variáveis em alface cultivada sob sistema hidropônico. Acta Scientiarum, 2004, 26, 2, 211-217.

PEREIRA, A. R.; VILLA NOVA, N. A.; SEDIYAMA, G. C. Evapotranspiração. Piracicaba: FEALQ, 1997. 183p.

RESENDE G. M. DE; ALVARENGA, M. A. R.; YURI, J. E.; SOUZA, R. J. DE; MOTA, J. H.; CARVALHO, J. G. DE; RODRIGUES JÚNIOR, J. C. Rendimento e teores de macronutrientes em alface tipo americana em função de doses de nitrogênio e molibdênio em cultivo de verão. Ciência e Agrotecnologia, 2009, 33, 1, 153163.

SANTOS, S. R.; PEREIRA, G. M. Comportamento da alface tipo americana sob diferentes tensões da água no solo, em ambiente protegido. Engenharia Agrícola, 2004, 24, 3, 569- 577.
SILVA, P. A. M.; PEREIRA, G. M.; REIS, R. P.; LIMA, L. A.; TAVEIRA, J. H. S. Função de resposta da alface americana aos níveis de água e adubação nitrogenada. Ciência e Agrotecnologia, 2008, 32, 4, 1266-1271.

SILVA, F. A. M.; VILAS-BOAS, R. L.; SILVA, R. B. DA. Resposta da alface à adubação nitrogenada com diferentes compostos orgânicos em dois ciclos sucessivos. Acta Scientiarum Agronomy, 2010, 32, 131-137.

SILVA, P. F. DA; SILVA, C. H. DA; SANTOS, J. C. C. DOS; SANTOS, M. A. L.; SANTOS, D. P. Avaliação de diferentes lâminas de água na cultura da alface (Lactuca sativa L.) na região alagoana. $8^{\circ}$ Simpósio Brasileiro de Captação e Manejo de Água de Chuva. Campina Grande (PB), 14 a 17 de agosto de 2012.

VASCONCELLOS, M. A. S. DE. Fundamentos de economia. 2 ed. São Paulo: Saraiva, 2007. p.246.

VILLAS BÔAS, R. L.; PASSOS, J. C.; FERNANDES, M.; BÜLL, L. T.; CEZAR, V. R. S.; GOTO, R. Efeito de doses e tipos de compostos orgânicos na produção de alface em dois solos sob ambiente protegido. Horticultura Brasileira, 2004, 22, 1, 28-34.

YURI, J. E.; SOUZA, R. J. DE; FREITAS, S. A. C. DE; RODRIGUES JÚNIOR, J. C.; MOTA, J. H. Comportamento de cultivares de alface tipo americana em Boa esperança. Horticultura Brasileira, 2002, 20, 229-232. 